\title{
Interaction of Downforce Generating Devices and Cooling Air Flow - A Numerical and Experimental Study on Open Wheeled Race Cars
}

\author{
Niklas Dyverfors, Kristoffer Borre, Christian Arnell and Jonathan Rice \\ Chalmers University of Technology
}

Copyright $(2012$ SAE International doi: $\underline{10.4271 / 2012-01-1165}$

\section{ABSTRACT}

This study reflects on two areas of vehicle aerodynamics, optimising cooling performance and features that will improve the handling of the car. Both areas will have a significant impact on the overall performance of the car and at the same time these areas are linked to each other.

The considered vehicle in this study was the Chalmers Formula Student 2011 Formula SAE car and the flow field was analysed using both numerical simulations as well as performing wind tunnel experiments on a 1:3-scale model of the car.

The focus on increasing downforce without increasing the aerodynamic drag is particularly good in Formula SAE since fuel economy is an event at the competition. Therefore, the intention of this work is to present a study on how undertrays with different design such as added foot plates, diffuser and strakes can improve the downforce and reduce the drag. Apart from this focus has been towards a common issue among open wheeled race cars with the radiator placed behind the front wheels and how changes in this area will influence the handling of the car. Interference effects between these parts were seen as well as the influence on the general aerodynamic performance of the car.

\section{INTRODUCTION}

If a race car is to perform at its peak you must optimize the power-to-weight ratio, handling and the aerodynamic properties of the car. The power-to-weight ratio is linked to the handling in the sense that a light weight car can easier achieve good handling characteristics. The handling is an area that can be improved by the aerodynamic characteristics of the car. This could be devices that create downforce but often this will lead to an increase in total vehicle weight. Therefore the task of optimizing the aerodynamics of the 2011 Chalmers Formula Student car, with respect to handling, will not involve any added pure aerodynamic devices. The work has instead focused on optimizing the parts that are required for legislative reasons as opposed to purely aerodynamics.

In order to optimize the power, which would directly increase the power-to-weight ratio, the engine needs to be able to run at the highest possible power output. To do this the radiator needs to dissipate the excess heat in a sufficient way. If the radiator is to perform in an optimal fashion, it needs to receive sufficient air with the correct parameters. This is important for the reason that the radiator in a sports car of the kind investigated transfers heat through convection and the most fundamental issue for this to work is good airflow. Sufficient cooling is an issue commonly experienced by Formula SAE cars, however after testing this has not proved to be an issue for the Chalmers Formula Student car.

Formula Student cars are design for competing on a very tight course and for that reason the car will reach relatively low speeds. An average speed on a Formula Student course is around 60kph and the cars seldom exceeds $100 \mathrm{kph}$.

\section{VEHICLE DATA}

The vehicle is a single seat open wheel racer, seen in Figure 1, that is designed and built based on the 2011 edition of the Formula SAE regulations [2]. The car is built on a tubular steel frame with a body, floor pan and diffuser made from two layers of TeXtreme ${ }^{\circledR}$, which is a Spread Tow Fabric, with a Nomex ${ }^{\circledR}$ honeycomb sandwich core. It is fitted with 
pullrod suspension in the front and pushrod suspension in the rear.

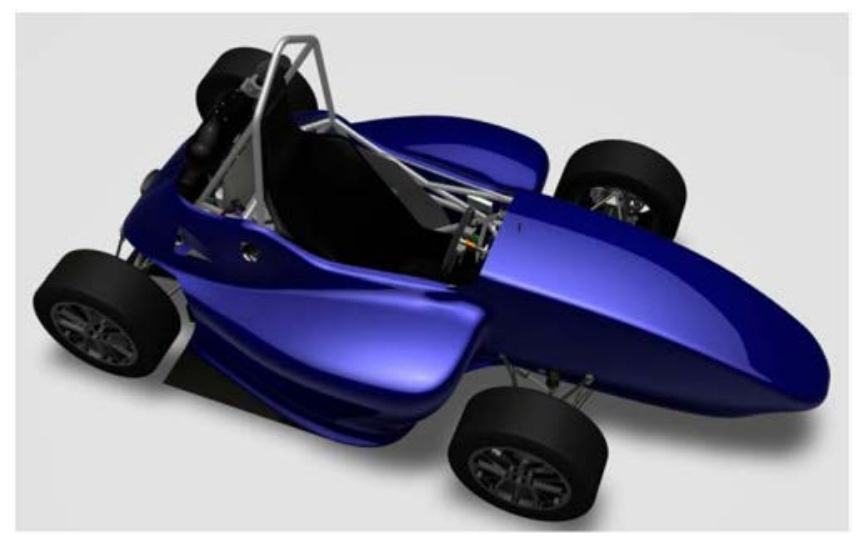

Figure 1. 2011 Chalmers Formula Student car

The power provided by a 600cc Yamaha engine producing 93hp. The SAE regulations [2] demand that the engine is fitted with a $20 \mathrm{~mm}$ restrictor.

Connected to this engine is a radiator made from aluminum with a core area of $0,09 \mathrm{~m}^{2}$ demanding an airflow of $0,3 \mathrm{kgs}^{-1}$ in order to provide sufficient cooling. When a fan is used it is an electrical fan mounted on a ducting that is attached to the radiator as seen in Figure2.

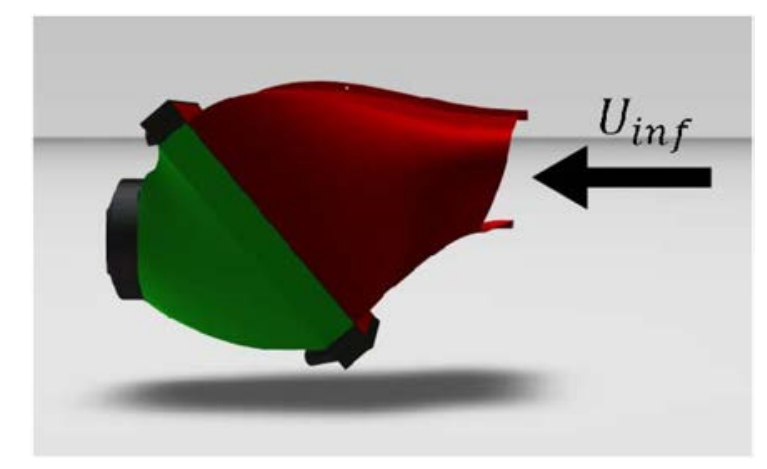

Figure 2. Cooling package with fan, rear ducting (green), radiator (between rear and front ducting) and front ducting (red)

\section{THEORY}

During the optimization of the aerodynamics of the 2011 Chalmers Formula Student car, in the area of vehicle performance on a track, the work has focused around two parameters; Lift coefficient, $C_{L}$, and Drag coefficient, $C_{D}$. Both of these parameters, often called shape functions, are based on the fundamental principle that moving air creates a dynamic pressure. This is described by the Bernoulli relationship:

$$
P_{0}=P+\frac{Q^{*} U^{2}}{2}
$$

where $\frac{\Omega^{*} U^{2}}{2}=$ dynamic pressure and $\mathrm{P}=$ static pressure.

What occurs when a lift force is generated can be described by a number of different theories. To give a general explanation of it we use a wing to simplify the reasoning. First we define a control volume around an infinitely long wing placed in an airflow. If we let the airflow enter the control volume with no upward or downward motion, let it flow around the wing and then leave the control volume we can see that the air that leaves the volume has picked up a downwards motion. This means that a force has been applied to the particles in the flow and for that reason there must be a reaction force on the wing it self which leads to that the wing will experience a lift force.

This phenomenon is what a device called a diffuser tries to prevent. A diffuser allows the air exiting the underside of the racecar to expand and decelerate cleanly, thereby lowering the backpressure on the flow under the racecar, this, in turn, accelerates the flow under the racecar lowering the static pressure on the underbody and creating downforce. To avoid the expansion of the air from the diffuser increasing at a high rate and causing turbulence, the inclination of the diffuser should lie in the region of 7-14 degree to the horizontal plane according to McBeath [3]. When the pressure difference is inverted. a low pressure zone is created on the underside of the vehicle, thus creating negative lift or downforce.

Drag is based on the same phenomena but the difference is that it can be split into three types according to Barnar [4] and Katz [6]:

1. Surface friction drag: The friction in the air that comes from the surface. Surface friction is considerably smaller than the other two.

2. Pressure drag: This is because when the vehicle moves through the air it gets a higher pressure at the front and a lower pressure wake at the rear of the vehicle. This pressure difference results in a force with the direction towards the lower pressure and therefore resisting the vehicles movement through the air.

3. Induced or vortex drag: There is generally a difference in pressure between the top and bottom side of the vehicle and as air is inclined to flow from regions of high pressure to regions of low pressure, swirling flow or vortexes are created. A large amount of energy goes into the formation of these vortexes; hence they are a source of drag. This phenomenon 
can be seen as vortexes on a rainy day from the rear upper corners of a car or from the wing tips on a plane.

Both $C_{D}$ and $C_{L}$ are dimensionless quantities which are used to quantify the drag and lift of an object respectively and are calculated using the following equation:

$$
\begin{aligned}
& C_{D}=\frac{1}{\text { Dynamic pressure } * A} * F_{x} \\
& C_{L}=\frac{1}{\text { Dynamic pressure } * A} * F_{z}
\end{aligned}
$$

In the case of cars, $\mathrm{A}$ is the frontal area in order to simplify the calculations both for $C_{D}$ and $C_{L}$ [4].

In order to optimize the performance of the engine, it requires sufficient and balanced cooling that provides a combustion chamber that is neither too hot, nor to cold, enabling efficient combustion without damaging vital and mechanical parts within the engine as discussed by Stone [5].

With a radiator comes a resistance in airflow and therefore increased drag. According to Kays and London [7] there is a parabolic growth of the flow resistance from an increasing Reynolds number. In this case an increase of the Reynolds number means an increase of the velocity. Christoffersen [1] states that in order to achieve the highest heat rejection with lowest possible drag, the velocity distribution on the front face of the radiator must be uniform.

This can be achieved with what Harris and Recant [ㅁ] states; the purpose of front ducting is to ensure an even distributed velocity distribution on the front face of the radiator and at the same time balance the pressure distribution at the inlet and outlet in order to minimize the drag from a sufficient airflow through the radiator.

According to Christoffersen [1] the best way to design the ducting in order to avoid separation, which would decrease the efficiency of the radiator, is to have a smooth expansion after the inlet that has a smaller area than the front face of the radiator. To further increase the performance of the ducting it should have rounded edges on the inlet.

\section{ANALYSIS}

All work has been performed using two methods, Computational Fluid Dynamics (CFD) and wind tunnel testing. At an early stage of the development process, the designs were assessed using CFD, to reduce the number of design iterations that were required to be manufactured and validated using wind tunnel testing.

\section{COMPUTATIONAL FLUID DYNAMICS}

This involved three softwares; Ansa (BetaCAE) to prepare and clean up the surfaces of the car and also create the triangular surface mesh. Sharc Harpoon was then used to create the volume mesh surrounding the car, simulating the wind tunnel, but it also generate a new surface mesh. The domain had its inlet 3 car lengths upstream and 8 car lengths downstream from the front of the nose. The height-to-width ratio of the domain was 1,6 for half of the car. Using two refinement zones to produce a finer mesh surrounding and behind the car together with the earlier mentioned settings resulted in a mesh for half the car that consisted of approximately 12,5 million cells. Scewness for these cells was kept below 0,98.

The third software to be used was Ansys Fluent to run the simulations with the realizable k-epsilon turbulence model and non equilibrium wall function. These settings are widely used within the automotive industry and thus the reason for choosing to use them in this study. Data and equations for a high performance radiator, as provided by Volvo Cars and Chalmers University of Technology, were used to calculate the viscous and inertial resistance for the radiator in this study. As for the fan, the manufacturer could supply sufficient information so that a second degree polynomial for the pressure jump could be calculated and used. The fan model that has been used is a lumped parameter model.

The simulations were all run with 1000 iterations in first order upwind after which they were switched to second order upwind for 3000 more iterations. Additional settings, as outlined below, were also applied:

- Gradient: Green-Gauss cell based

- Solutions control:

$\circ$ Pressure $=0,25$

$\circ$ Momentum = 0,6

- Turbulent kinetic energy $=0,6$

- Turbulent dissipatient ratio $=0,6$

- Turbulent viscosity $=0,9$

- Reference area (front area): 0,457

The reason for using this configuration of software was due to the requirement of a fast development process and based on recommendations from the Department of Applied Mechanics at Chalmers University of Technology. In order to compare the results with a previous study [1], the velocity,

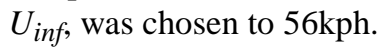

The results presented in APPENDIXA for $C_{D}, C_{L}$ and mass flow are a mean value of the 500 last iterations. $F_{X, Z}$ are 
SAE paper 2012-01-1165 Copyright (C) 2012 SAE International. This paper is posted on this site with permission from SAE International,

calculated based on the results from the simulations using equation2a and $\underline{2 b}, S=1,225 \mathrm{kgm}^{-3}$ and $\mathrm{A}=0,914 \mathrm{~m}^{2}$.

\section{WIND TUNNEL TESTING}

To validate the results from the CFD a one third scale-model was used for the testing. The model is a rapid prototype consisting of body, frame, seat, driver, suspension and wheels replicating the full scale car design. The wheels are held in place with two $10 \mathrm{~mm}$ in diameter steel tubes as the suspension material could not support the wheels during the conditions in the wind tunnel as seen in Figure3.

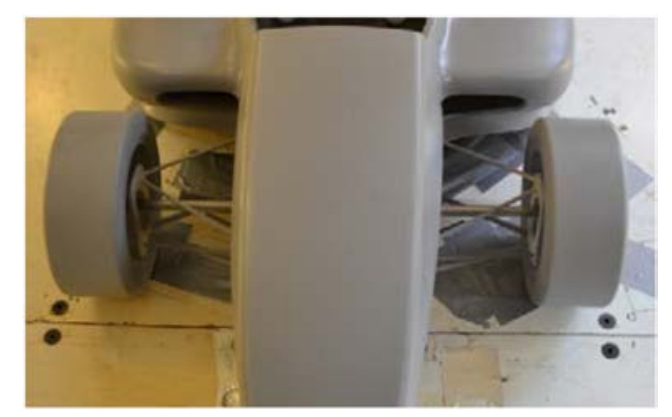

Figure 3. Suspension wind tunnel model

It also has a simulated radiator with a honeycomb core with 2 layers of steel wire mesh on each side. This is in accordance with the recommendations of Söderblom []ㅡ where the airflow and pressure drop from a real radiator can be simulated, as seen in Figure 4. During the test a stationary road was used.

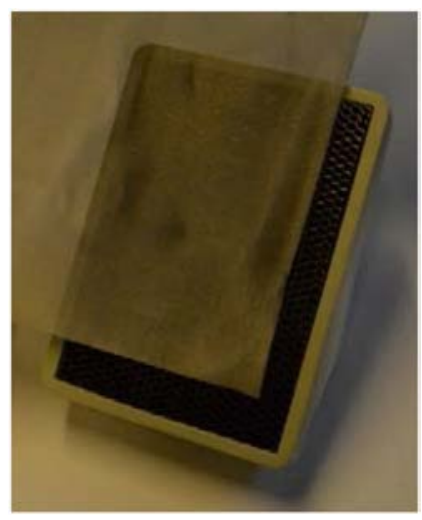

Figure 4. Radiator for wind tunnel model

The wind tunnel used is located at Chalmers University of Technology and under the authority of the Department of Applied Mechanics. The data for the wind tunnel are as follows:

\section{- Göttingen type (closed circuit)}

$$
\begin{aligned}
& \circ \text { Dimensions } \mathrm{w} * \mathrm{~h} * \mathrm{l}=1,8 * 1,25 * 3 \mathrm{~m} \\
& \text { - Speed range }=0-63 \mathrm{~ms}^{-1}
\end{aligned}
$$

$\circ$ Free steam turbulence intensity $<0.1 \%$

$\circ$ Fan power $=220 \mathrm{~kW}$

- Force measurement:

- Six component FFA Y-603 strain gauge type balance

- Six component RUAG model 196-6H balance

- Visualization:

- Smoke

$\circ$ Tufts

- Surface flow visualization fluids

During testing the balance was used to provide all numerical data. No pressure gauges were used to measure the pressure on the surface or around the model. For visualization, smoke and yarn strings were used as seen in Figure5 and Figure6.

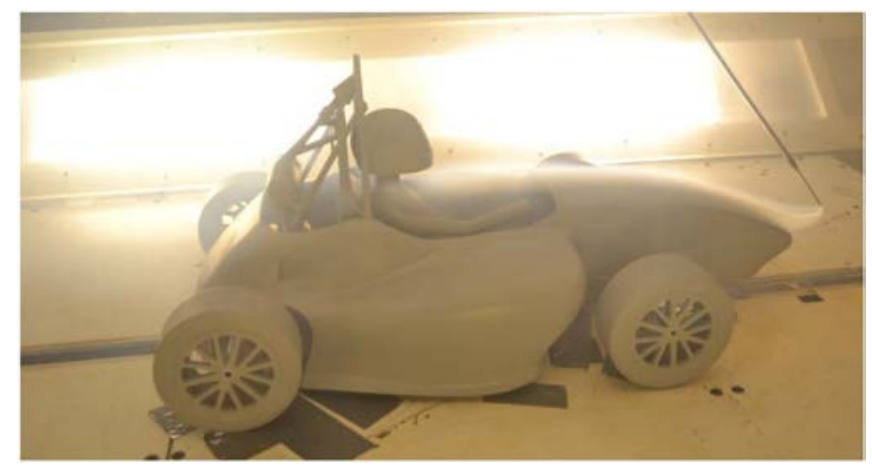

Figure 5. Visualization using smoke on wind tunnel model

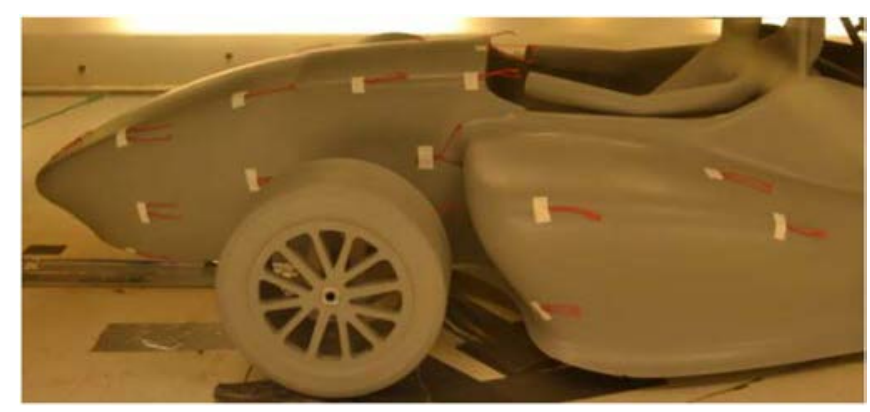

Figure 6. Wind tunnel model with yarn strings

$C_{D, L}$ are calculated based on the results from the wind tunnel tests using equation $2 \mathrm{a}$ and $\underline{2 \mathrm{~b}}$ with $\Omega=1,225 \mathrm{kgm}^{-3}$ and $\mathrm{A}=$ $0,914 \mathrm{~m}^{2}$. 


\section{CASE STUDY}

\section{COMPUTATIONAL FLUID DYNAMICS}

To be able to locate patterns and see connections between different parts of the car and the impact on the aerodynamic properties, the result is based on 10 separate simulations completed on a half car as seen in Table1or APPENDIXA. This study is focusing on the aerodynamic performance of the car and not the cooling performance, even though the aerodynamic impact from the cooling package is analyzed, and therefore are all simulations done during isothermal conditions.

The cases were chosen with respect to different velocities and setups of the car. This velocity was chosen so it could be compared with a previous study [1] but also as this reflects the average conditions that a Formula Student car will experience. All simulations have been performed in straight line conditions.

In these cases three different diffusers and one version of foot plates were used which are described below.

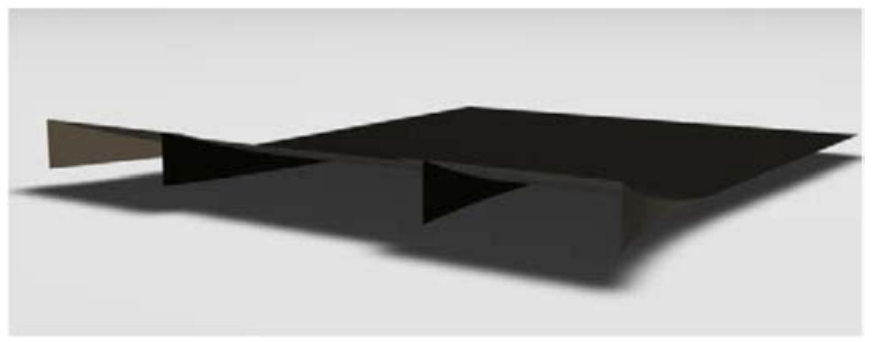

Figure 7. Basic

1)Basic: The simplest of the proposed designs. It has an angle of 9 degrees and is fitted with 2 strakes.

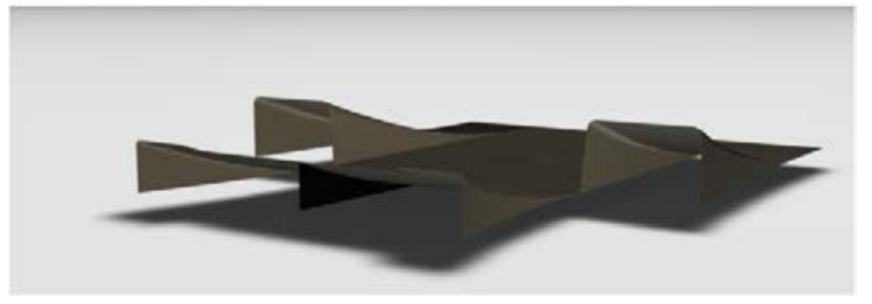

Figure 8. Diffuser A
2) Diffuser A: Consists of three sections. The two front sections have an angle of 12degree with a convex curvature. The rear section has the same curvature but is fitted with one strake. All sections expand sideways as well.

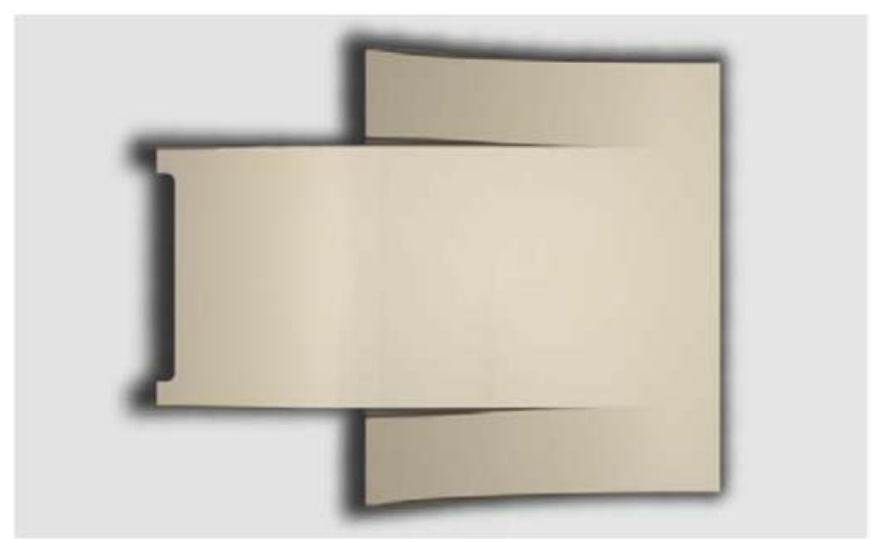

Figure 9. Diffuser AR

3) Diffuser AR: Is the same as Diffuser A apart from that the rear section has straight edges, no expansion sideways, and is fitted with two strakes which is explained in "RESULTS FROM CFD, AERODYNAMIC FEATURES". The weight of this part is $600 \mathrm{~g}$.

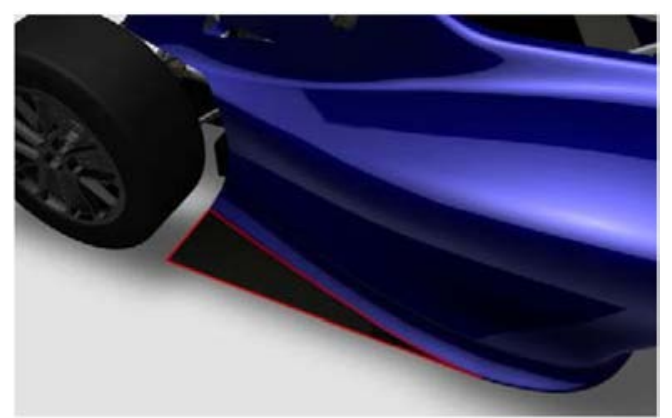

Figure 10. Foot plates marked with red

4) Foot plates: Is an extension strait backwards of the floor pan behind the sidepod up until the rear wheels.

The 10 alternative cases that were simulated are the following: 
Table 1. The setup for the different CFD cases

\begin{tabular}{|c|c|c|c|c|c|c|c|}
\hline \multirow{2}{*}{ Case } & \multirow{2}{*}{$\begin{array}{l}\text { Uinf } \\
\text { kph }\end{array}$} & \multirow{2}{*}{ Fan } & \multirow{2}{*}{ Diffuser } & \multirow{2}{*}{$\begin{array}{l}\text { Foot } \\
\text { plate }\end{array}$} & \multicolumn{2}{|c|}{ Ducting } & \multirow{2}{*}{ Surface } \\
\hline & & & & & Front & Rear & \\
\hline Case 1 & 80 & No & Type A & No & Yes & Yes & Class B \\
\hline Case 2 & 80 & $7 "$ & Type A & No & Yes & Yes & Class B \\
\hline Case 3 & 80 & 7" & Type A & No & No & Yes & Class B \\
\hline Case 4 & 80 & 7" & Basic & No & Yes & Yes & Class B \\
\hline Case 5 & 80 & $7 "$ & Type AR & No & Yes & Yes & Class B \\
\hline Case 6 & 56 & 9" & Type AR & No & Yes & Yes & Class B \\
\hline Case 7 & 80 & 9" & Type AR & No & Yes & Yes & Class B \\
\hline Case 8 & 56 & 9" & Type No & No & Yes & Yes & Class B \\
\hline Case 9 & 56 & 9" & Type AR & Yes & Yes & Yes & Class A \\
\hline Case 10 & 56 & 9" & Type AR & Yes & Yes & Yes & Class A \\
\hline
\end{tabular}

\section{WIND TUNNEL TESTING}

The purpose of 8 alternative setups was to validate the results from the different cases simulated with the CFD. The wind tunnel testing became an extension of the work after the simulations were completed, however it was not possible to manufacture a model precisely according to the CFD model or possible to modify in the same way. The effects this had on the results are discussed later in VALIDATION WITH WIND TUNNEL TEST. The model could however be modified in such ways which resulted in the configurations that can be seen in Table 2 or APPENDIX B. The diffuser used on the model was Diffuser AR.

\section{COOLING DESIGN}

The ducting has been design from data collected at 56kph which is the average speed for a Formula Student endurance track. The approach taken to solve the very common issue regarding cooling of a Formula Student car has been to use ducting both before and after the radiator as recommended by Barnar[4]. The main goal with the design has been to feed air with a attached flow through the radiator at a lower velocity than the velocity of the air surrounding the vehicle, $U_{\text {inf }}$. To do this the ducting has been designed according to a number of parameters:
Intake

To obtain a constant supply of air into the ducting, the intake was placed in a high pressure zone at the front of the right side pod. Unfortunately this is an area which experiences turbulence due to the proximity of the wheel and suspension. To minimize the effects caused by the interaction of these components, especially the wheel, the intake was placed as close to the side panels as possible. The high placement is due to the advantage in yaw conditions but this investigation is not dealt with in this paper.

\section{Outlet}

When the air has passed through the radiator and fan, it needs to exit into the ambient air and to ensure this, the outlet has been placed in a low pressure zone which improves the effectiveness of the fan.

\section{DuctinginFrontoftheRadiator}

The two main features of the front ducting are to slow down the air velocity and reduce turbulence in the air. This was done by smoothly increasing the volume with a factor of 2,2 from inlet to radiator, as seen in Figure11. To avoid causing undue turbulence in the air during this expansion the walls should have a smooth curvature. The reason to prevent turbulence is because if it continues through the radiator, cooling efficiency can be adversely affected. To maintain the attached flow through the radiator, the walls should have a perpendicular angle against the radiator in order to make $U_{\text {radiator }}$ perpendicular against the radiator.

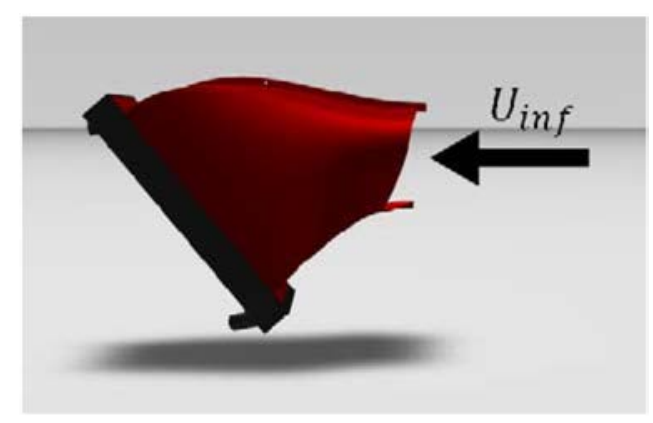

Figure 11. Front ducting and radiator

\section{DuctingAftertheRadiator}

To optimize the cooling performance the pressure build up should be evenly distributed across the whole surface of the radiator and to achieve this the fan has been mounted behind the radiator, as seen in Figure 12. This means that the pressure drop created from the fan can equalize in the rear ducting and create an even spread of pressure over the radiator [7]. 


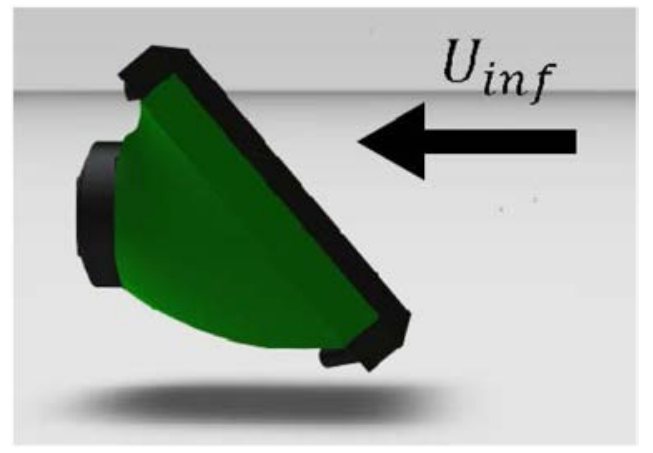

Figure 12. Rear ducting with radiator

\section{RESULTS FROM CFD, COOLING}

All results for this section are presented in APPENDIXA and the setup for each case can also be seen in Table 1. The velocity, $U_{\text {inf }}$, which is of practical focus, is $56 \mathrm{kph}$ but a higher velocity has been used in order to compare the result with [1] and see how the flow behaves at higher speeds. The simulations have been performed as described in "ANALYSIS".

The engine described in "VEHICLE DATA" requires an airflow of $0,3 \mathrm{kgs}^{-1}$ to provide sufficient cooling. This study focused on how the aerodynamics of the car can be modified to achieve this figure. As seen in case 3 the mass flow through the radiator at $80 \mathrm{kph}$ is $0,15 \mathrm{kgs}^{-1}$ which is half of what it should be at 56kph even though a 7inch fan is used. As seen in Figure13 there is a localized pressure increase at the top of the radiator and not an equal pressure over the whole radiator which is a demand for adequate cooling.

To understand how ducting affects $C_{D}$ and $C_{L}$ this result compared with case 2 shows that you get $\Delta C_{D, 3-2}=-0,048$, equal to a $7 \%$ decrease, and $\Delta C_{L, 3-2}=0,0265$, equal to a 15 $\%$ increase, when front ducting is added.

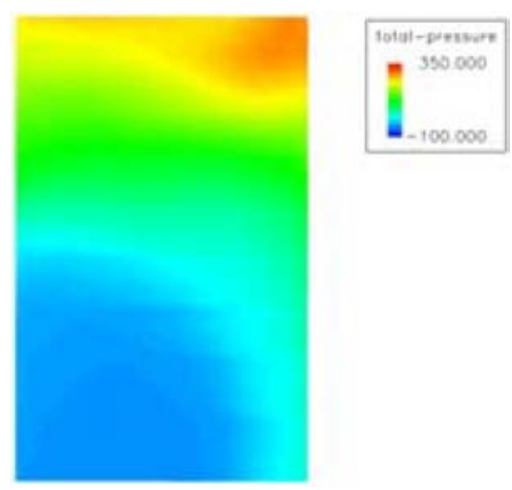

Figure 13. Total pressure, front of the radiator, case 3
If the fan would be replaced with front ducting, according to case 1 , the mass flow would increases to $0,26 \mathrm{kgs}^{-1}$ which is not enough sufficient since this was at $80 \mathrm{kph}$. The phenomenon with higher pressure being experienced at the top of the radiator was reduced as seen in Figure14.
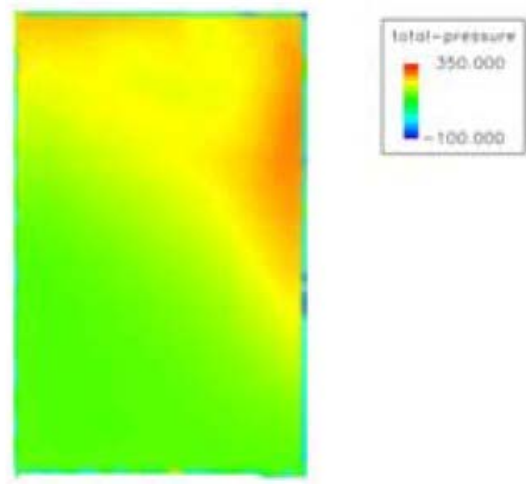

Figure 14. Total pressure, front of radiator, case 1

Shown in case 7 is the result of combining the identified pattern from these two cases into a setup with a 9 inch fan and a front ducting. This is the setup that gives the best air flow through the radiator, $0,39 \mathrm{kgs}^{-1}$. This is still at $80 \mathrm{kph}$ but in case 6, 8, 9 and $10 U_{\text {inf }}$ is decreased to $56 \mathrm{kph}$ which is the investigated velocity and for that condition the radiator has a sufficient mass flow of $0,31 \mathrm{kgs}^{-1}$. As seen in Figure 15 the pressure is more evenly spread over the whole surface.

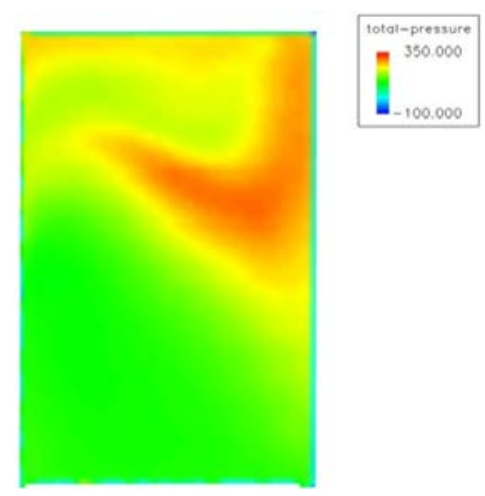

Figure 15. Total pressure, front of radiator, case 7

If we want to see how the fan size affect $C_{L}$ and $C_{D}$ the result from case 7 compared with case 5 gives $\Delta C_{D, 5-7}=-0,034$, equal to a $6 \%$ decrease, and $\Delta C_{L, 5-7}=0,0327$, equal to a $16 \%$ increase, when the fan is increased from 7inch to 9inch.

To summarize the cooling and aerodynamic performance: from case 3 , with no front ducting, and case 2, with front ducting, both with the same fan, it can be seen that there is a increase of $48 \%$ in mass flow, at a speed of $80 \mathrm{kph}$. By adding front ducting $C_{D}$ will decrease with $7 \%$ while $C_{L}$ will 
increase with $15 \%$. At the same time a bigger fan will decrease $C_{D}$ with $6 \%$ while $C_{L}$ will increase with $16 \%$.

The result from this setup can be compared with the result presented in the study where the 2007 Chalmers Formula Student car was investigated [1]]. This study was based on the same type of car under the same type of conditions but with a much less complex design of the front ducting and no fan. In [1] the maximum air flow through the radiator was $\sim 0,19 \mathrm{kgs}$ ${ }^{-1}$ with a ducting in front compared with $0,31 \mathrm{kgs}^{-1}$. The radiator area in [1] was $\sim 0,081 \mathrm{~m}^{2}$.

The disadvantages from the design of the ducting are that 1 out of 4 walls on the ducting has a too great inclination of the wall which creates undesired turbulence along the surface. Also, 1 out of 4 walls of the ducting is not perpendicular to the radiator which will create turbulence in the radiator. The reason for this was due to the chosen manufacturing method for the ducting and lack of space in the sidepod.

\section{AERODYNAMIC FEATURES}

To maximise the gains from aerodynamic devices with respect to handling, the work has aimed to optimize the parts already required on the car by competition rules. This has involved the body, floor pan, seat and firewall in the following ways:

Nose: If the most forward point is placed low you will obtain airflow over the nose that has the effect of pushing it down which leads to an increase in vehicle front end grip. Preferably this airflow should consist of as little turbulent flow as possible.

Sidepods: With a droplet design of the sidepods you can encourage air to follow the sidepod and therefore minimize the wake behind the vehicle that creates drag.

Floor pan: With one large smooth floor pan you can help to achieve an attached flow under the car which can lead to downforce.

Diffuser: Bending the rear section of the floor pan protecting the engine by 7-14degree [3] upwards can lead to downforce.

Cooling outlet: Placing the outlet in a rear low pressure zone can help to decrease the wake behind the car.

Seat and firewall: To reduce drag the seat and firewall should extend as little as possible around the driver and if it does a tilted angle is preferred [10].

\section{RESULTS FROM CFD, AERODYNAMIC FEATURES}

All results for this section are presented in APPENDIXA and the velocity, $U_{i n f}$, that is studied is $56 \mathrm{kph}$ but a higher velocity has been used in order to compare the result with [1] and see how the flow behaves at higher speeds. The simulations have been performed as described in "ANALYSIS" and the setup for the different cases can be seen in Table1 and APPENDIXA.

The baseline setup during the simulations has been the configuration stated in case 4, as seen in Figure 16. This setup gave a $C_{D}=0,5622$ and a $C_{L}=0,1337$. This means that $C_{D}$ for a formula style car is relatively good but the vehicle has a positive $C_{L}$ which gives an undesired lift force.

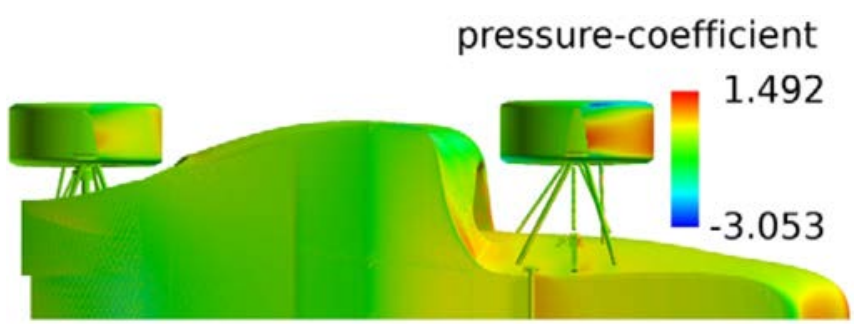

Figure 16. Pressure coefficient for case 4

Case 2 has a setup where the Basic diffuser has been replaced with Diffuser $\mathrm{A}$. This change has a smaller affect on $\Delta C_{D, 4-2}$ $=-0,0069$ but the big difference is $\Delta C_{L, 4-2}=-0,2848$ where Diffuser A reduces $C_{L}$ to $C_{L}=-0,1511$. The change in $C_{L}$ from a positive to a negative value changes the direction of the force from a lift to a down force; so instead of being lifted by the air, the air now pushes the vehicle down and increase the grip of the car which can add to improved handling. As seen in Figure17 the pressure below the car from the middle and rearwards has decreased.

pressure-coefficient

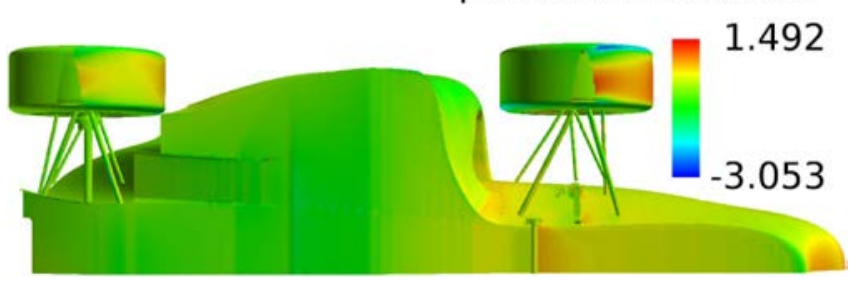

Figure 17. Pressure coefficient for case 2

A drawback discovered was that the diffuser expanded both upwards and sideways. This expansion created turbulence along the sides as seen in Figure 18. The result of this was that the resulting pressure was not as low as it could be if the turbulent flow was eliminated, as seen in Figure 19. Therefore Diffuser A was redesigned with straight edges and 
two strakes instead of one and after that called Diffuser AR. This design however increased $C_{D}$ with $\Delta C_{D, 2-5}=0,008$, which is equal to the Basic diffuser, but managed to decrease $C_{L}$ with $\Delta C_{L, 2-5}=-0,0489$ as seen in case 5 .

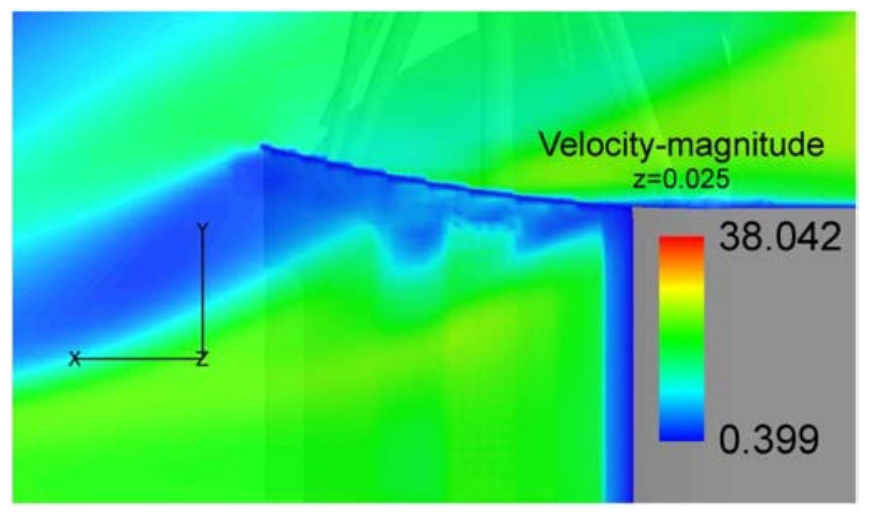

Figure 18. Velocity coefficient for Diffuser A at $\mathrm{z}=30 \mathrm{~mm}$ in case 2

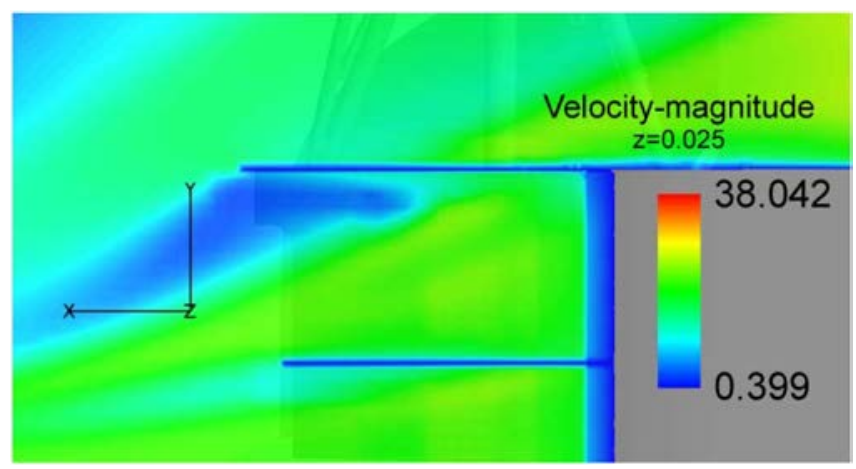

Figure 19. Velocity coefficient for Diffuser AR at $\mathrm{z}=30 \mathrm{~mm}$ in case 5

As stated in "RESULT FROM CFD COOLING, CFD" a 7inch fan does not provide a sufficient mass flow through the radiator. Therefore we can investigate how a bigger fan affects $C_{D}$ and $C_{L}$ by comparing case 5 and case 7 . When the fan was changed to a 9inch fan $C_{D}$ decreased with $\Delta C_{D, 5-7}=$ $-0,034$, which is equal to $6 \%$, and $C_{L}$ increased with $\Delta C_{L, 5-7}$ $=0,0327$. In order to cope with this increase in $C_{L}$ the model was fitted with foot plates, as in case 9. To evaluate and quantify the performance from the foot plate's case 9 can be compared with case 6 which is the same setup, excluding foot plates. From this we can see that both $C_{D}$ and $C_{L}$ decrease with $\Delta C_{D, 6-9}=-0,008$ and $\Delta C_{L, 6-9}=-0,0865$ respectively. With the setup chosen as in case 9 it is clear that the foot plates provides $40 \%$ of the downforce, which means a increase of downforce with $69 \%$ from case 6 . The reason for this is due to that the foot plates are not only an extension of the floor pan, where the downforce is produced, it also works as a protection for the diffuser. A small gap exists between the foot plates and the wheel, which prevents the turbulent air from the surface of the tyre to be thrown under the floor pan and into the diffuser, thus reducing its efficiency. The result from this can be seen in Figure20.

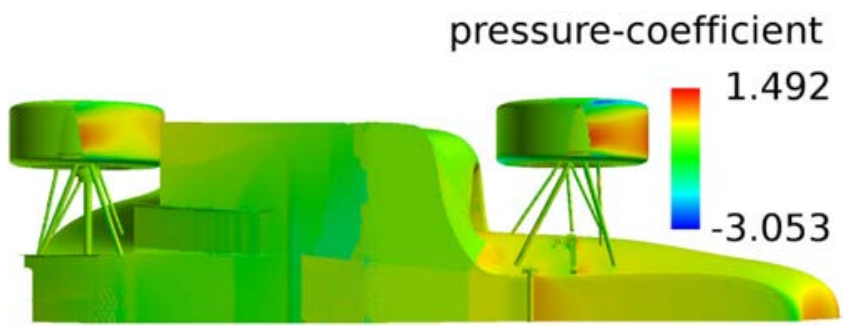

Figure 20. Pressure coefficient for case 9

To validate the changes made, one of the simulations is performed without these added parts and this is case 8 as seen in Figure21. Here it is clear that the diffuser and foot plates had a positive effect as the results are $C_{D, 8}=0,5192$ and $C_{L 8}$ $=0,4466$ compared with $C_{D, 9}=0,5170$ and $D_{L, 9}=-0,214$.

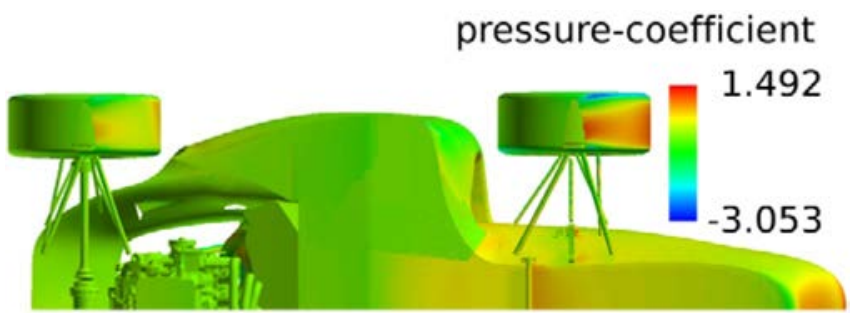

Figure 21. Pressure coefficient case 8

As a final improvement the surfaces of the body were redone with a lower tolerance and that decreased both $C_{L}$ and $C_{D}$ with $\Delta C_{D, 9-10}=-0,013$ and $\Delta C_{L, 9-10}=-0,086$ for the final result, $C_{D, 10}=0,504$ and $C_{L, 10}=-0,3$. The reason for this result is that during redesign, the floor area was slightly increased and could therefore provide more downforce. It also lead to a slightly bigger front area which would increase $C_{D}$ but since the sidepods were altered to account for this they could allowed some of the air to pass on the inner side of the wheels instead, as seen in Figure22. This also means that the sidepods feed more air around the diffuser which increases the performance of it [3]. 

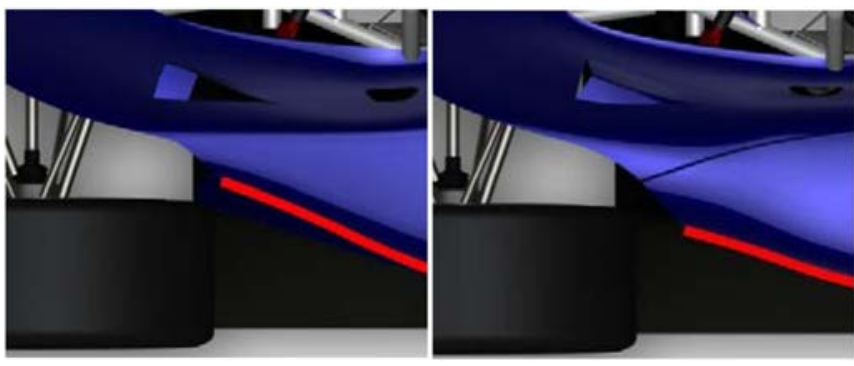

Figure 22. To the left class $A$ surfaces and to the right class $B$

When case 2, 4, 5 and 9, which all consists of different aerodynamic features, are investigated due to the mass flow through the radiator, it can be seen that the aerodynamic features have no or a very small impact on the cooling performance.

\section{RELATION BETWEEN COOLING AND AERODYNAMIC PROPERTIES}

When analyzing the effects on the drag from the cooling package the discovery was made that the setup with the lowest drag is not to have any openings in the sidepods, thereby eliminating the cooling drag. Since this is not an option for the car investigated the setup with as low drag as possible was the setup with front ducting and a 9inch fan. This setup has proven more advantageous than a setup without a fan but with a front ducting and a setup with a fan but without a front ducting. As mention in "RESULTS FROM CFD, COOLING" this is also the setup that provides the best air flow through the radiator. However there is a trade-off between airflow through the radiator and $C_{D}$ and $C_{L}$; an increase in airflow will lead to a decrease in $C_{D}$ and a increase in $C_{L}$. This phenomenon corresponds well with the result that Christoffersen [1] presents.

For the impact on the cooling performance due to the different aerodynamic features no such relation was found.

\section{VALIDATION WITH WIND TUNNEL TEST}

All data/results for this section are presented in APPENDIX B. The wind tunnel tests have been performed in the wind tunnel and with the model described in "ANALYSIS".

The cases that were performed are:
Table 2. The setup for the wind tunnel cases

\begin{tabular}{|l|}
\hline Setup: \\
\hline Baseline (Bl) \\
\hline Bl with left intake covered \\
\hline Bl with both intakes covered \\
\hline Bl with foot plates \\
\hline Bl - diffuser \\
\hline $\begin{array}{l}\text { Bl yawed 5deg with sealed } \\
\text { cockpit in the rear }\end{array}$ \\
\hline
\end{tabular}

The baseline is the setup seen in Figure6 with Diffuser AR, class A surfaces, front and rear ducting and with an opening for a 9inch fan but not the fan itself.

The purpose of this was to validate the results from the CFD. The results from the wind tunnel deviate significantly from the CFD results. The reasoning behind this is that since the wind tunnel model is a physical model of the car it has a much smaller level of details than the CFD model which will affect the results. However, the biggest reason for the difference in $C_{D}$ and $C_{L}$ comes from the fact that the wind tunnel does not have rotating wheels or a mowing ground which the CFD simulations has. The rotating wheels would create an upstream of air which could create the difference in $C_{L}$ that can be noticed when comparing the results. The steel tubes used for holding the wheels also created some extra turbulence.

The important fact from comparing the results is that the patterns for both the CFD and the wind tunnel correlate well. The wind tunnel results also present two conditions that were not simulated in the CFD, closed side pods and yaw condition of 5 degrees to the left.

From the CFD it was clear that to minimise $C_{D}$ through modification of only the cooling package the optimum solution was to use a front ducting and a 9inch fan. That setup in the CFD is equivalent to the base line setup in the wind tunnel testing. From a further investigation it is clear that $C_{D}$ could be reduced even further by not allowing the air through the sidepods and instead sealing it at the front opening and allow the air to pass around it. The drawback is obviously that there would be no cooling effect should the radiator be placed in this location.

From the two cases with foot plates and without diffuser the same pattern as from the CFD is clear. By adding foot plates 
you get a decrease in $C_{L}$ and without the diffuser there is an increase of $C_{L}$ which corresponds very well with case 8 and case 9 from the CFD.

\section{CONCLUSIONS}

For a Formula Student car such as the one investigated there can be a great increase in cooling efficiency by using front ducting. A ducting with a smooth volume increase before the radiator can increase the airflow through the radiator by $48 \%$ at a velocity of $80 \mathrm{kph}$.

It was found that the solutions used in this study in order to increase the mass flow through the radiator will give a decrease in $C_{D}$ and an increase in $C_{L}$. For the opposite, the impact on cooling performance from aerodynamic features, no such relation was found and therefore the conclusion was made that the aerodynamic features investigated in this study do not affect the cooling performance.

For this study the solution with the best trade-off between cooling performance and $C_{D}$ and $C_{L}$ was to use a front ducting with a 9inch fan together with Diffuser AR and foot plates.

The usage of a diffuser for a Formula Student car was motivated by the result from this study and with the right design it can provide a considerable amount of downforce. In this study it was shown that the increase in downforce from Diffuser AR on its own was $129 \%$ to a weight of $600 \mathrm{~g}$.

In this specific case, the downforce could be increased by 69 $\%$ by adding foot plates to a weight of $50 \mathrm{~g}$ which makes a strong motivation for their use.

\section{ACKNOWLEDGEMENTS}

The authors would like to express their gratitude to Dr Christoffer Landström, Daryosh Farin and Chalmers for making wind tunnel testing possible. A special acknowledgement to David Söderblom for supervising the work both regarding CFD and wind tunnel testing. Furthermore Saab Automobile AB should be acknowledge for the sponsorship and manufacturing of the wind tunnel model.

\section{REFERENCES}

1. Christoffersen, L., Söderblom, D., and Löfdahl, L., "Improving the Cooling Airflow of an Open Wheeled Race Car,” SAE Technical Paper 2008-01-2995, 2008, doi: 10.4271/2008-01-2995.

2. 2011 Formula SAE Rules, SAE International, 2010.

3. McBeath, S. (2006) Competition Car Aerodynamics: A Practical Handbook. Sparkford: Haynes Publishing ISBN 1844252302[x]
4. Barnar, R H. “Road Vehicle Aerodynamics Design”, $2^{\text {nd }}$ edition, MechAero Publishing 2001 ISBN:

978-0-9540734-0-4

5. Stone, R. "Introduction to Internal Combustion Engines" $3^{\text {rd }}$ edition, McMillan Press LTD 1999, ISBN 0-333-74013-0

6. Katz, J. "Race Car Aerodynamics - Designing for Speed", Robert Bentley, 1995, ISBN 0-8376-0142-8

7. Kays, W.M. and London, L.A. "Compact Heat Exchangers”. McGraw-Hill Book Company, $3^{\text {rd }}$ edition, 1984.

8. Harris, T. A., Recant, I. G. "Investigation in the 7-by 10Foot Wind Tunnel of Ducts for Cooling Radiators within an Airplane Wing”, N.A.C.A. Report no. 743.

9. Söderblom, D. "Correlation of Pressure Drop over a Simplified and Detailed Radiator Geometry", Chalmers University of Technology 2006, Division of Vehicle Safty, 2006:89

10. Doddegowda, P., Bychkovsky, A., and George, A., "Use of Computational Fluid Dynamics for the Design of Formula SAE Race Car Aerodynamics," SAE Technical Paper 2006-01-0807, 2006, doi:10.4271/2006-01-0807.

\section{DEFINITIONS/ACRONYMS/ ABBREVIATIONS}

\section{CFD}

Computational Fluid Dynamics

$P_{0}$

Pressure constant

$\mathbf{P}$

Static pressure

९

Air density

A

Frontal area

$U_{\text {inf }}$

Free stream velocity

$U_{\text {radiator }}$

Perpendicular velocity in to the radiator

$C_{D}$

Drag coefficient 
$C_{L}$

Lift coefficient

$F_{X}$

Force, x-component

$\boldsymbol{F}_{\mathbf{Z}}$

Force, z-component

\section{CONTACT}

Niklas Dyverfors

Chalmers University of Technology

Applied Mechanics

SE-412 96 Gothenburg

SWEDEN

dyverfor@student.chalmers.se 


\section{APPENDIX}

\section{APPENDIX A}

\begin{tabular}{|c|c|c|c|c|c|c|c|c|c|c|c|}
\hline \multicolumn{12}{|c|}{ CFD (half a car) } \\
\hline \multicolumn{7}{|c|}{ Setup } & \multicolumn{5}{|c|}{ Results } \\
\hline \multirow{2}{*}{ Case } & \multirow{2}{*}{ Uinf[kph) } & \multirow{2}{*}{ Fan } & \multirow{2}{*}{ Aero. Fetures } & \multicolumn{2}{|c|}{ Ducting } & \multirow{2}{*}{ Surfaces } & \multirow{2}{*}{$\mathrm{Cv}$} & \multirow{2}{*}{$C L$} & \multirow{2}{*}{$\begin{array}{l}\text { Mass flow } \\
\text { trough radiator } \\
{\left[\mathrm{kgs}^{-1}\right]}\end{array}$} & \multirow{2}{*}{$F x[\mathrm{~N}]$} & \multirow{2}{*}{$\mathrm{Fz}[\mathrm{N}]$} \\
\hline & & & & Front & Rear & & & & & & \\
\hline Case 1 & 80 & No & Diffuser A & Yes & Yes & Class B & 0,5583 & $-0,1503$ & 0,26 & 77,173 & $-20,776$ \\
\hline Case 2 & 80 & Yes- 7" & Diffuser A & Yes & Yes & Class B & 0,5555 & $-0,1511$ & 0,22 & 76,786 & $-20,886$ \\
\hline Case 3 & 80 & Yes- 7" & Diffuser A & No & Yes & Class B & 0,6035 & $-0,1776$ & 0,15 & 83,421 & $-24,549$ \\
\hline Case 4 & 80 & Yes- 7" & Basic & Yes & Yes & Class B & 0,5622 & 0,1337 & 0,22 & 77,712 & 18,481 \\
\hline Case 5 & 80 & Yes- 7" & Diffuser AR & Yes & Yes & Class B & 0,5635 & $-0,2$ & 0,21 & 77,892 & $-27,646$ \\
\hline Case 6 & 56 & Yes- 9" & Diffuser AR & Yes & Yes & Class B & 0,525 & $-0,1275$ & 0,31 & 35,559 & $-8,636$ \\
\hline Case 7 & 80 & Yes- 9" & Diffuser AR & Yes & Yes & Class B & 0,5295 & $-0,1673$ & 0,39 & 73,192 & $-23,126$ \\
\hline Case 8 & 56 & Yes- 9" & No diffuser & Yes & Yes & Class B & 0,5192 & 0,4466 & 0,31 & 35,166 & 30,249 \\
\hline Case 9 & 56 & Yes- 9" & Diffuser AR + foot plates & Yes & Yes & Class B & 0,517 & $-0,214$ & 0,31 & 35,017 & $-14,495$ \\
\hline Case 10 & 56 & Yes- 9" & Diffuser AR + foot plates & Yes & Yes & Class A & 0,504 & $-0,3$ & 0,31 & 34,312 & $-20,424$ \\
\hline
\end{tabular}


SAE paper 2012-01-1165 Copyright (C) 2012 SAE International. This paper is posted on this site with permission from SAE International, and is for viewing only. Further use or distribution of this paper is not permitted without permission from SAE

\section{APPENDIX B}

\begin{tabular}{|l|c|c|c|c|c|}
\hline \multicolumn{5}{|c|}{ Wind tunnel (whole car) } \\
\hline \multicolumn{2}{|c|}{ Setup } & \multicolumn{5}{c|}{ Result } \\
\hline Configurations: & $\mathrm{U}\left[\mathrm{ms}^{-1}\right]$ & $F_{x}[\mathrm{~N}]$ & $F_{Z}[\mathrm{~N}]$ & $C_{D}$ & $C_{L}$ \\
\hline Baseline & 40,3327 & 28,845 & 5,884 & 0,285 & 0,058 \\
\hline Left intake covered & & & & & \\
\hline Both intakes covered & 40,3694 & 28,723 & 5,048 & 0,283 & 0,050 \\
\hline Foot plates & 40,3840 & 28,350 & 4,597 & 0,279 & 0,045 \\
\hline No diffuser & 40,2841 & 28,241 & 1,298 & 0,280 & 0,013 \\
\hline Yawed 5deg, with sealed cockpit in the rear & 40,1952 & 27,550 & 4,636 & 0,274 & 0,046 \\
\hline Yawed 5deg, with open cockpit in the rear & 40,1511 & 28,532 & 5,704 & 0,285 & 0,057 \\
\hline
\end{tabular}

The Engineering Meetings Board has approved this paper for publication. It has successfully completed SAE's peer review process under the supervision of the session organizer. This process requires a minimum of three (3) reviews by industry experts.

All rights reserved. No part of this publication may be reproduced, stored in a retrieval system, or transmitted, in any form or by any means, electronic, mechanical, photocopying, recording, or otherwise, without the prior written permission of SAE. ISSN 0148-7191
Positions and opinions advanced in this paper are those of the author(s) and not necessarily those of SAE. The author is solely responsible for the content of the paper.

\section{SAE Customer Service:}

Tel: 877-606-7323 (inside USA and Canada)

Tel: 724-776-4970 (outside USA)

Fax: 724-776-0790

Email: CustomerService@sae.org

SAE Web Address: http://www.sae.org

Printed in USA 